See Article page 375 .

\section{Commentary: A prompt diagnosis and timely surgical intervention can improve survival after traumatic cardiac herniation}

\author{
Juan A. Muñoz-Largacha, MD, and \\ Benjamin Wei, MD
}

\begin{abstract}
A case of pleuropericardial rupture with right-sided cardiac herniation after high-impact blunt chest trauma is presented by LeBlanc and colleagues. ${ }^{1}$ As mentioned by the authors and previously reported in the literature, pericardial rupture and associated right-sided cardiac herniation after blunt chest trauma is uncommon ${ }^{2,3}$; however, it must be in the differential diagnosis of any patient who experienced blunt chest trauma and it should be recognized promptly to improve survival. Given the high prehospital mortality of this type of injury, with most of the cases identified postmortem, a clear diagnostic approach has been difficult to establish. Even if a patient survives to the hospital, mortality rates are still $>50 \% .{ }^{4}$ In this case, the patient arrived to the trauma center 4 hours after the initial event, which is surprising given the severity of his injury. On initial assessment, and after fluid resuscitation/blood transfusion and intubation, a chest radiograph was performed showing dextrocardia, which should be an alarming sign for any clinician. Focused assessment with sonography for trauma (FAST) was also performed; however, findings were limited because of extensive subcutaneous emphysema and abnormal heart location. FAST is a useful and available tool in trauma settings, but given the lack of operator
\end{abstract}

\footnotetext{
From the Division of Cardiothoracic Surgery, Department of Surgery, University of Alabama at Birmingham, Birmingham, Ala.

Disclosures: The authors reported no conflicts of interest.

The Journal policy requires editors and reviewers to disclose conflicts of interest and to decline handling or reviewing manuscripts for which they may have a conflict of interest. The editors and reviewers of this article have no conflicts of interest.

Received for publication Aug 14, 2020; revisions received Aug 14, 2020; accepted for publication Aug 14, 2020; available ahead of print Aug 19, 2020.

Address for reprints: Benjamin Wei, MD, Division of Cardiothoracic Surgery, Department of Surgery, University of Alabama at Birmingham, 703 19th St, S, Zeigler Research Building, Room 701, Birmingham, AL 35294 (E-mail: bwei@uab. edu).

JTCVS Techniques 2020;4:380-1

2666-2507

Published by Elsevier Inc. on behalf of The American Association for Thoracic Surgery. This is an open access article under the CC BY-NC-ND license (http:// creativecommons.org/licenses/by-nc-nd/4.0/).

https://doi.org/10.1016/j.xjtc.2020.08.045
}

Check for updates

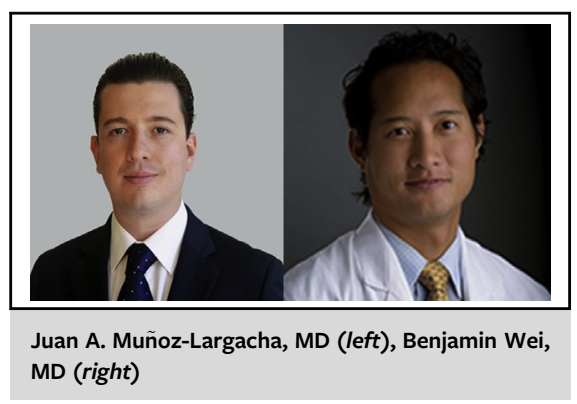

CENTRAL MESSAGE

A rare case of pleuropericardial rupture with right-sided cardiac herniation after blunt chest trauma is presented. A prompt diagnosis and timely surgical intervention are essential to improve survival.

expertise and variability and increased difficulty for obtaining adequate ultrasound windows, FAST may not be the best diagnostic tool in these cases. In this case of hemodynamic stability, a computed tomography angiogram was performed revealing cardiac herniation into the right pleural cavity with associated torsion and pulmonary and venous narrowing. As expected, computed tomography better demonstrated anatomy and cardiac herniation. However, performing this test will highly depend on the patient's hemodynamic status and can also delay prompt surgical intervention. An emergent bilateral anterolateral thoracotomy with manual reduction of the heart into the pericardial sac and repair of the pleuropericardial defect with mesh prosthesis was performed with immediate improvement of patient hemodynamics. The initial approach in these cases should follow the trauma Advanced Cardiovascular Life Support algorithm; however, clinicians should recognize the potential for pleuropericardial rupture and cardiac herniation in high-impact blunt chest trauma. Cardiovascular instability that mimics tamponade physiology can be seen, which can fluctuate with changes in patient position and may not respond to resuscitation and inotropic support. ${ }^{4}$ The importance of a prompt diagnosis relies on the fact that once cardiac herniation is recognized, the therapeutic approach is clearly defined and effective. Nevertheless, high clinical suspicion, physical exam, and diagnostic adjuncts such as electrocardiography, chest radiograph, and FAST may help expedite diagnosis, and theoretically 
improve survival. Electrocardiography may show axis deviation, ST-segment changes secondary to coronary artery compression, or in some cases right bundle branch block. Chest radiograph in this case showed dextrocardia that should set off alarms for cardiac herniation given the fact that the incidence of dextrocardia in the general population is extremely low, ${ }^{5,6}$ and in this setting is more likely to be related to recent traumatic injury. Detorsion of the heart should be accompanied by repairing the pericardial defect-if primary repair is attempted, consideration needs to be given to permitting egress of fluid from the pericardial sac and avoiding constriction of the heart, which may be edematous due to fluid resuscitation and/or cardiac contusion. The safer option may be pericardial reconstruction as performed here. This case presented by LeBlanc and colleagues ${ }^{1}$ will help readers to be more aware of the potential for cardiac herniation in the setting of high-impact blunt chest trauma. We would like to highlight the importance of a prompt diagnosis because treatment is simple and effective with encouraging results after early operative intervention. $^{4}$

\section{References}

1. LeBlanc N, Tan L. Pericardial rupture with cardiac herniation following blunt thoracic trauma. J Thorac Cardiovasc Surg Tech. 2020;4:375-7.

2. Fulda G, Brathwaite CE, Rodriguez A, Turney SZ, Dunham CM, Cowley RA. Blunt traumatic rupture of the heart and pericardium: a 10-year experience (1979-1989). J Trauma. 1991:31:167-73.

3. Clark DE, Wiles CS III, Lim MK, Dunham CM, Rodriguez A. Traumatic rupture of the pericardium. Surgery. 1983;93:495-503.

4. Sherren PB, Galloway R, Healy M. Blunt traumatic pericardial rupture and cardiac herniation with a penetrating twist: two case reports. Scand J Trauma Resusc Emerg Med. 2009; 17:64.

5. Offen S, Jackson D, Canniffe C, Choudhary P, Celermajer DS. Dextrocardia in adults with congenital heart disease. Heart Lung Circ. 2016;25:352-7.

6. Casey B. Two rights make a wrong: human left-right malformations. Hum Mol Genet. 1998;7:1565-71. 